\title{
The effects of dispersion on frequency-dependent predation of polymorphic prey
}

\author{
J. S. Gianino and \\ J. S. Jones
}

Department of Genetics and Biometry,

University College London, Wolfson House,

4 Stephenson Way, London NW1 2HE, U.K.

Populations of coloured baits were presented to wild birds. When the two bait colours were randomly intermingled, the birds ate an excess of the commoner form. However, rarer prey were preferred if they were aggregated together. The fitness of alleles under apostatic natural selection may thus be related to spatial pattern as well as to frequency.

\section{INTRODUCTION}

When faced with a diversity of resources predators may forage so as to maximize energy gain and thus reduce the cost of hunting. Such optimal foraging often leads to a concentration on certain prey items or particular foraging sites at the expense of others (Stephens and Krebs, 1986). Prey may evolve a diversity of pattern which leads predators to identify them as distinct food items and to avoid rare morphs at the expense of common. Alternatively, they may become widely dispersed and foil predators by ensuring that the encounter rate is below that necessary to maintain an attacker's attention. Each of these evolutionary responses by prey depends on circumventing mechanisms of optimal foraging. They can act to promote genetic polymorphism through apostatic selection (Clarke, 1962) and to increase the species diversity of communities subject to predation (Murdoch and Oaten, 1975).

Although there is a shortage of good examples of apostatic selection in the wild, rare forms of polymorphic prey are indeed protected against predation when experimentally presented to predators. Pastry baits of an unusual colour gain protection through their rarity (Allen and Clarke, 1968; Allen, 1988), and this is sometimes true of semi-natural prey such as polymorphic prey stuffed with pastry (Bantock and Harvey, 1974) or baited cockle or mussel shells (Croze, 1970). Polymorphism may reduce the proportion of a population taken by predators (Croze, 1970). Dispersion may also protect against predation, as widely spaced plants suffer fewer attacks from insects than do those clumped together (Kareiva, 1986) and dispersed cryptically-coloured baits are eaten less than are aggregated (Tinbergen et al., 1967).

In spite of the experimental work by genetists on polymorphism and by ecologists on dispersion, little is known of how spacing might affect the fitness of genetically diverse prey. Here we describe experiments on the effects of changes in spatial distribution on the relative fitness of morphs in artificial polymorphic prey. The efficacy of frequency-dependent selection by predators seems to depend strongly on the patterns of dispersion of each morph.

\section{MATERIALS AND METHODS}

We used a design related to that of Allen and Clarke (1968), who presented coloured pastry baits to wild passerine birds. Each bait consisted of uncooked pastry (one part lard to three parts flour by weight) made into $7 \mathrm{~mm} \times 3.5 \mathrm{~mm}$ cylinders and dyed with the food colours Pointing Apple Green K6027 or Pointing Brown K6024. The experiments were carried out on closely cut lawns in Oxford (43 experiments) and in Regents Park, London (eight experiments). One experiment was performed each day; and the whole set of experiments carried out over two years. Baits were laid out in a ten by ten metre square at a density of two per metre square. In each experiment, baits were presented in the ratio of nine brown to one green; or nine green to one brown; or with equal frequencies 
of the two colours. For each of the frequencies, the baits were presented in one of two spatial arrays: randomly placed over the grid (using a random number table to assign position); or aggregated, with one of the colours occupying a group of adjacent grid squares. When a particular colour in the aggregated array was present at a frequency of 0.1 it occupied a line of ten squares at the edge of the grid, with the edge involved changed at random for each experiment. Colours at frequencies of 0.5 were aggregated into the left, right, top or bottom sectors of the grid, alternated at random. Each experiment was continued until about 100 baits had been taken. The position and number of baits eaten was recorded and the remainder removed.

The results were analysed using $\beta$, the coefficient of selection developed by Manly et al. (1972) for experiments such as these, calculated so that increasing values reflect an increased preference for green baits. The measure is best seen as the relative risk of predation for each class of bait, its value indicating the chance that the next to be taken will be a green if equal numbers of the two classes are available. $\beta$ values were arcsine transformed, to give a measure which varies from 0 to 90 degrees.

\section{RESULTS}

The main predators were Blackbirds Turdus merula, Starlings Sturnus vulgaris, with occasional Song Thrushes Turdus philomelos, Chaffinches Fringilla coelebs, Robins Erithacus rubecula and House Sparrows Passer domesticus. The requisite 100 baits were usually consumed within four to five hours of being set up. Baits near the centre of the grid were more likely to be eaten than those at the edge. In ten of the experiments involving randomly distributed prey, baits in the central squares had a significantly higher probability of being taken than those at the edge, while in only one were prey taken significantly more often from the edge. In five there was no significant differences between central and peripheral squares. These differences may arise because predators concentrate 'on areas of effectively higher prey density (Curio, 1976).

Table 1 and Figure 1 show the patterns of predation of the two colours at different frequencies and with contrasting patterns of spatial distribution. Relatively fewer green baits were eaten in all experiments, with the mean transformed $\beta$ values always below 45 . However, there were also marked differences between treatments. In experi-

Table 1 Mean arcsine-transformed $\beta_{t}$ values (with $95 \%$ confidence limits), measuring preference for green baits

(i) Bedford College London.

\begin{tabular}{|c|c|c|c|c|}
\hline \multirow[b]{2}{*}{ Dates } & \multirow{2}{*}{$\begin{array}{l}\text { Frequencies } \\
\text { (green) }\end{array}$} & \multicolumn{2}{|l|}{ Distribution } & \multirow[b]{2}{*}{$t$-test } \\
\hline & & Aggregated & Random & \\
\hline $25 / 11 / 81-3 / 12 / 81$ & $0 \cdot 9$ & $\begin{array}{l}21 \cdot 98 \pm 5 \cdot 63 \\
(N=3)\end{array}$ & $\begin{array}{l}35 \cdot 07 \pm 6 \cdot 58 \\
(N=5)\end{array}$ & $3.99 * *$ \\
\hline
\end{tabular}

(ii) Lovelace Road, Oxford:

\begin{tabular}{|c|c|c|c|c|}
\hline \multirow[b]{2}{*}{ Dates } & \multirow{2}{*}{$\begin{array}{l}\text { Frequencies } \\
\text { (green) }\end{array}$} & \multicolumn{2}{|l|}{ Distribution } & \multirow[b]{2}{*}{$t$-test } \\
\hline & & Aggregated & Random & \\
\hline $24 / 7 / 82-20 / 1 / 83$ & 0.9 & $\begin{array}{l}27 \cdot 24+4 \cdot 12 \\
(N=8)\end{array}$ & $\begin{array}{l}39 \cdot 26 \pm 6 \cdot 67 \\
(N=8)\end{array}$ & $3 \cdot 69^{* * * * *}$ \\
\hline $30 / 1 / 84-23 / 2 / 84$ & $0 \cdot 5$ & $\begin{array}{l}30 \cdot 60 \pm 9 \cdot 41 \\
(N=5)\end{array}$ & $\begin{array}{l}31 \cdot 89 \pm 4 \cdot 72 \\
(N=5)\end{array}$ & $0 \cdot 34 \mathrm{~ns}$ \\
\hline $27 / 6 / 83-26 / 11 / 83$ & $0 \cdot 1$ & $\begin{array}{l}35 \cdot 02 \pm 6 \cdot 16 \\
(N=9)\end{array}$ & $\begin{array}{l}22 \cdot 71 \pm 8 \cdot 05 \\
(N=8)\end{array}$ & $2 \cdot 98^{* *}$ \\
\hline$t$-test & & $2 \cdot 40^{*}$ & $3 \cdot 89 * * *$ & \\
\hline
\end{tabular}

*** $P<0.002$

** $P<0.01$

* $P<0.05$. 


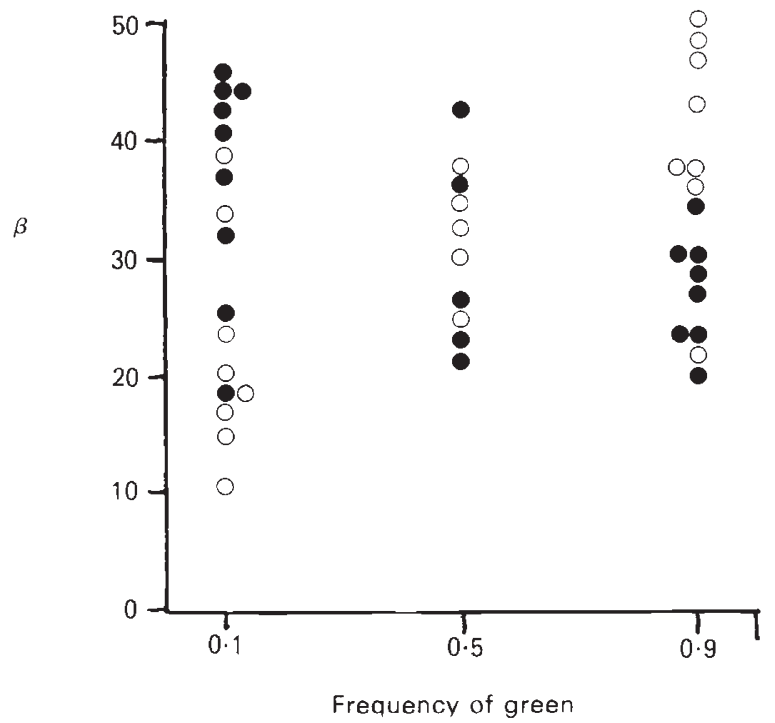

Figure 1 Changes in the relative predation on green baits with frequency and dispersal pattern. Preference for green increases with increasing value of $\beta$ (see text). Solid circles $=$ aggregated distribution of baits; open circles $=$ random distribution of baits.

ments in which baits were distributed at random there was a marked effect of frequency on the probability of predation, greens being relatively protected more when rare than when common. This frequency dependent advantage of rare morphs scattered among individuals of a more common phenotype is similar to that found by Allen and by others (Allen, 1988).

Baits presented in aggregated distributions suffer the opposite pattern of predation: there is an increased probability of rare prey being eaten so that it is positively disadvantageous for unusual forms to be aggregated together. The effect does not arise because the groups of aggregated rare prey were at the edges of the grid but in spite of it, since predators concentrate their attentions towards the centre of the array. Rare prey hence receive protection only when dispersed among prey of contrasting appearance, and spatial distribution has as important an effect on their fitness as does frequency.

\section{DISCUSSION}

In these experiments, the frequency dependent advantage of rare polymorphic prey is manifest only when they are distributed among potential food items of a different appearance. This effect of spatial patterning probably results from the feeding behaviour of predators. Optimal foraging is determined by a balance between the cost of obtaining an item and the benefit to be gained from eating it, and is important in a variety of situations (Pyke, 1984; Greenwood, 1984; Stephens and Krebs, 1986). Predators as different as protozoa and birds concentrate on relatively common items of prey, so that the proportion of a particular item eaten does not reflect its abundance in the population (Murdoch and Oaten, 1975). The behaviour may arise because of the formation of learned preferences for abundant prey (Tinbergen, 1960) which are maintained only if regularly reinforced by a successful encounter. Any rare and widely dispersed food item will appear at intervals too long to maintain the necessary response. Although there is disagreement about the exact mechanisms involved (Guilford and Dawkins, 1987), such behaviour will favour rare morphs or rare species of prey.

Predators hunting in this way will tend to avoid widely spaced prey. Many cryptic and palatable prey are solitary (de Ruiter, 1952; Edmunds, 1974), and Croze (1970) and Tinbergen et al. (1967) found that widely spaced cryptic baits suffered relatively less predation, perhaps because of a concentration by predators on a small area to reduce the time and energy involved in hunting (Curio, 1976). This behaviour will penalise groups of palatable prey, both because any searching image is more frequently reinforced and because any tendency to concentrate on the site of a successful first encounter with a particular food item will ensure that the predator takes more of them. Rare prey may hence loss their advantage as they become aggregated. In the switching model of Murdoch and Oaten (1975) it is assumed that alternate prey are mixed together, so that relative rather than absolute prey density is important. Increased predation on rare prey aggregated together might hence arise from their higher relative density in their own section of the array. In such circumstances, the tendency of individual predators to sample "runs" of particular prey items (Royama, 1970) may lead to a disadvantage of aggregated prey with the same appearance and to the loss of the frequency-dependent advantage which arises when they are scattered among contrasting baits.

In some circumstances, aggregation may be advantageous for potential prey. Distasteful and warningly coloured animals are often clumped together, so that a predator's initial experience is unlikely to be forgotten before another prey item is encountered (Gittleman and Harvey, 1980). 
There are also analogies with the aggregations of certain plants which increase their efficiency of exploitation of pollinators by reducing the distances which must be travelled (Real, 1983). Although predation is often thought to act on a larger spatial scale than does competition (Schmitt, 1985 ) our results suggest that even within a 10 by 10 metre grid spatial patterning can alter the chance of attack. Aggregation may therefore reduce the likelihood of a competitively superior species replacing others in communities (such as those on rocky shores; Sih et al., 1985) exposed to intense predation.

It is clear that the frequency-dependent advantage of rare palatable prey may depend upon their spatial patterning, and can be lost or even reversed if this pattern is not appropriate. As there is an overall preference for brown baits in all our experiments, none of the frequencies or patterns presented would lead to the maintenance of polymorphism at the frequencies used if the two colours are seen as alleles, or of coexistence if they are regarded as competing species. However, these observations do show that fitness of an allele or persistence of a species may depend on its position in relation to others as much as on its relative abundance.

Acknowledgements We thank Mr K. P. Anderson for making the baits, and Dr J. A. Allen for his helpful comments on the manuscript.

\section{REFERENCES}

ALLEN, J. A. 1988. Frequency-dependent selection by predators. Phil. Trans. Roy. Soc. Lond. Ser. B., 319, 485-503.

ALLEN, J. A. AND ANDFRSON, K. P. 1984. Selection by passerine birds is anti-apostatic at high prey densities. Biol. J. Linn. Soc: Lond., 23, 237-246.

ALLEN, J. A. AND CIARKE, B. C. 1968. Evidence for apostatic selection by wild passerines. Nature, 220, 501-502.

BANTOCK, C, R. AND HARVEY, P. H. 1974. Colour polymorphism and selective predation experiments. J. Biol. Educ., 8, $323-329$.
CLARKE, B. C. 1962. Balanced polymorphism and the diversity of sympatric species. Syst. Ass. Publ., 4, 47-70.

CROZE, II. 1970. Searching images in carrion crows. $Z$ Tierpsychol., Suppl., 5, 1-85.

CURIO, E. 1976. The Ethology of Predation. Springer-Verlag, Berlin.

DE RUITER, L. 1952. Some experiments on the camouflage of stick caterpillars. Behaviour, 4, 222-232.

EDMUnds, M. 1974. Defence in Animals. Longman, Harlow.

GITSLEMAN, J. H. AND HARVEY, P. H. 1980. Why are distasteful prey not cryptic? Nature, 286, 149-150.

GREENWOOD, J. J. D. 1984. The functional basis of frequencydependent food selection. Biol. J. Linn. Soc. Lond., 23 , $177-199$.

GUILFORD, T. AND DAWKINS, M. S. 1987. Search images not proven: a reappraisal of recent evidence. Anim. Behav., 35 , $1838-1845$.

HORSLEY, D. T., LYNCH, B. M., GREENWOOD, J. J. D., HART)MAN, B. AND MOSELY, S. 1979. Frequency-dependent selection by birds when the density of prey is high. J. Anim. Ecol., 48, 483-490.

KAREIVA, P. 1986. Patchiness, dispersal and species interactions: consequences for communities of herbivorous insects. In Diamond, J. M. and Case, T. J. (eds) Community Ecology, Harper and Row, New York, pp. 192-206.

MAN1_Y, B. F. J., MILLER, P. AND COOK, L. M. 1972. Analysis of a selective predation experiment. Amer. Nat., 106, 719 736.

MURDOCH, W, W. AND OATEN, A. 1975. Predation and population stability. Adv. Ecol. Res., 9, 1-131.

PYKE, G. H. 1984. Optimal foraging theory: a critical review. Ann. Rev. Ecol. Syst., 15, 523-575.

REAL, L. 1983. Pollination Biology. Academic Press, New York. ROYAMA, T. 1970. Factors governing the hunting behaviour and selection of food by the Great Tit (Parus major L.). J. Anim. Ecol., 39, 619-668.

SCHMITT, R. J. 1985. Competitive interactions of two mobile prey species in a patchy environment. Ecology, 66,950-958.

SHI, A., CROWLEY, P., MCPEEK, M., PETRANKA, J. AND STROH. MEIER, K. 1985. Predation, competition and prey communities: a review of field experiments. Ann. Rev. Ecol. Syst., 16, 269-311.

STEPHENS, D. W. AND KREBS, J. R. 1986. Foraging Theory. Princeton University Press, Princeton, New Jersey.

TINBERGEN, L. 1960. The natural control of insects in pinewoods. I. Factors influencing the intensity of predation by song birds. Arch. Neerl. Zool., 13, 265-336.

TINBERGEN, N., IMPEKOVEN, M. AND FRANCK, D. 1967. An experiment on spacing-out as a defence against predation. Behaviour, 28, 307-321. 